\title{
Study on snoring habit in healthy population of Eastern Odisha
}

\author{
Devi $E^{1}$, Sahu $S^{2}$, Ray $S^{3}$ \\ ${ }^{1}$ Dr. Ellora Devi, Professor, Department of Physiology. ${ }^{2}$ Dr. Samir Sahu, Professor, Department of Medicine. \\ ${ }^{3}$ Dr. Subhashree Ray, Professor, Department of Biochemistry, IMS \& Sum Hospital, Siksha 'O' Anusandhan University, \\ Bhubaneswar, Odisha, India.
}

Address for Correspondence: Dr. Ellora Devi, Email: elloraray@gmail.com

\begin{abstract}
Introduction: Snoring caused due to relaxation of upper airway tract leading to partial closure of the respiratory passage and characteristic snoring sound with reduced oxygen entry into lungs. Estimates of prevalence of snoring ranges from 5$44 \%$ of the general population. As per the gender distribution $24-50 \%$ men \&14-30\% women had snoring habits. Methods: It was single Centre cross sectional study done by Department of Physiology, IMS \& SUM Hospital in apparently healthy attendants accompanying patients using 'Snore Survey' questionnaire, Berlin Questionnaire. Results: There were 550 participants. Out of which $59.72 \%$ of men, $40.20 \%$ of women snored, $47.46 \%$ from both sexes were unaware of their snoring habit. $25.6 \%$ of all snorers confirmed daytime sleepiness. Prevalence of snoring increased in both sexes with increase in age. In males, the highest prevalence rate of snoring was obtained in the age group 50 -59, out of which $19.5 \%$ had moderate and $14.6 \%$ had habitual snoring. $10.6 \%$ of the males in the age group 55-69 years had clinically suspected Obstructive Sleep Apneas. For females, the highest prevalence rate of snoring occurred at age 40-49years with $17.8 \%$ having moderate and $7.1 \%$ habitual snoring, whereas clinically suspected Obstructive Sleep Apneas among the female was $8 \%$. Conclusion: Snoring a commonly ignored problem in our society, unless treated leads to risk of metabolic syndrome, Diabetes, CVS diseases like Hypertension, Arrhythmias\& death.
\end{abstract}

Keywords: BMI, Clinically Significant Obstructive sleep apnoea, Excessive Day time Sleepiness, Prevalence, Snoring.

\section{Introduction}

Snoring is multi factorial. From an anatomical standpoint, snoring is caused due to reduced crosssectional airway size in the nasopharynx, oropharynx and hypopharynx. During sleep, there is increase in upper airway activity leading to snoring and upper airway obstruction followed by arousal. Arousal activates the pharyngeal muscles and restores airway patency resulting in breathing. Richard B. Berry et al [1], demonstrated decrease in genioglossus muscle activation during inspiration.

Snoring is a common sleep problem with significant public health concern. Currently snoring is recognised as an important cause of medical morbidity \& mortality Epidemiological studies reported the higher prevalence of snoring among men which ranges from 5-44\% [2] \& $14-30 \%$ [3] in women. Obstructive sleep Apnoea

Manuscript received $10^{\text {th }}$ August 2016

Reviewed: $25^{\text {th }}$ August 2016

Author Corrected: $8^{\text {th }}$ September 2016

Accepted for Publication $22^{\text {nd }}$ September 2016
(OSA) characterized by recurrent episodes of partial or complete collapse of the upper airway during sleep producing a characteristic sound called snoring, leading to derangement in gas exchange \& recurrent arousals from sleep. OSA is considered as one of several potentially treatable contributors to systemic hypertension, associated with coronary artery disease, stroke, congestive heart failure, atrial fibrillation, increased motor vehicle accident rate, day time sleepiness, Diabetes, impaired quality of life, and increased mortality [4,5]. It is an important social nuisance, and contributes to impaired sleep quality of the bed partner.

\section{Methods}

A cross sectional study was carried out on a sample of adults who were attending/ accompanying patients at IMS \& SUM Hospital, Bhubaneswar. As a referral hospital, people from different regions of the state come here for treatment. 
A pretested \& corrected questionnaire was developed to objectively quantify sleepiness \& sleep problems among the participants. The corrected final version of the questionnaire included socio- demographic characteristics as well as height, weight, Body Mass Index (BMI) and sleep related problems like snoring, witnessed apnoeas by a spouse or bed partner and excessive day time somnolence. Informed consent was obtained from each participant and the questionnaire was explained to the participant.

Participants taking drugs inducing sleep, having chronic illness and consuming alcohol were excluded from the study. Each participant answered the questionnaire on site and was asked to discuss or confirm events like snoring and apneas.

Consecutive apparently healthy attendants in age group of 20-69 years were selected from those attending outdoor at IMS \& SUM Hospital, Bhubaneswar. Face to face interview using 'snore survey' questionnaire adopted from the Berlin Questionnaire (Appendix) [6]. Period of study was from April 2014 - May 2015.

Detailed information regarding snoring, included snoring loudness, snoring frequency, bothersome snoring and non-bothersome snoring were recorded along with age, sex, height, weight, neck circumference and blood pressure.

The Berlin Questionnaire sleep study method was appropriate for the tertiary care level hospital, as the patients came from different parts of the state to this hospital. Part of 'Snore Survey' questionnaire. (Adopted from Category 1 symptom details from Berlin Questionnaire) [6].

Q-1. Do you snore or you have been told you do?

- Yes

- $N o$

- Do not know

If yes:

If you snore:

Q-2. Snoring Loudness?

- Louder than breathing

- Loud as talking

- Louder than talking

- Very loud. Can be heard in adjacent rooms
Q-3. Snoring frequency?

- Almost every day

- 3-4 times/wk

- 1-2 times/wk

- 1-2 times/month

- Never or nearly never

Q-4. Has your snoring ever bothered other people?

- Yes

- No

Q-5. Has anyone noticed that you quit breathing during your sleep?

- Nearly every day

- 3-4 times /wk

- 1-2 times /wk

- 1-2 times/month

- Never /nearly never.

\section{Definitions}

- Snoring classification (1) Never/non snorers for those who had no such event, (2) Moderate or occasional snorers for those who snore for 1-3 times/week, (3) Habitual snorers for those with history of snoring of more than 3 times/ week.

- Apneas. Witnessed breathing interruptions during sleep. It is classified as never in those without the event and present in those with the event.

- The Epworth Sleepiness Scale (ESS) [7] was used to determine excessive day time sleepiness. It is an eight item self-administered questionnaire. Possible score ranges were from 0 to 24. For this study, an ESS score of more than 11 was taken to mean Excessive day time sleepiness EDS.

Clinically Suspected Obstructive Sleep Apnoea (CSOSA) was defined in accordance with the 2001 International Classification of Sleep Disorders ${ }^{[4]}$; habitual and loud snoring, witnessed apnoea and EDS.

Body Mass Index (BMI) was calculated using weight in Kilograms over height in meters squared.

Statistical Analysis- Data were analysed using the SPSS software version 20. Univariate analysis between snoring, CSOSA and sex and age was done \& statistical significance was found. Chi square test was used to test for association between habitual and moderate snoring and with other parameters like age and sex as shown in my research. 


\section{Results}

550 people participated in the study by questionnaire method of those 2\% (11-participants) did not respond. Incomplete information was provided by another 6 participants. Information was complete in the remaining 533 included till final analysis. The overall response was $96.90 \%$.

The general characteristics of the study sample 231(43.33\%) of the participants were female while 302(42.7\%) were male with their ages ranging from $20-69$ years. The overall mean age of participants was $35 \pm 3.84$ years, in males mean age was $38 \pm 5.16$ years and in females $41.4 \pm 7.1$ years. In male participants the mean BMI was $28.9 \pm 3.44$, and in female participants it was $30.2 \pm 4.12$. In $40.52 \%$ of all the participants there was reported history of snoring; while it was $42.7 \%$ in males and $40.2 \%$ in females. $47.46 \%$ couldn't confirm their snoring habit \& $25.6 \%$ agreed of daytime sleepiness. (Table-I)

Table-I: Snore Survey.

\begin{tabular}{|c|c|c|c|c|}
\hline & Male & Female & Total & Percent (\%) \\
\hline Participants & 302 & 231 & 533 & $100 \%$ \\
\hline Snorer & $129(42.7 \%)$ & $87(40.2 \%)$ & 216 & $40.52 \%$ \\
\hline Non-snorer & 130 & 123 & 253 & $47.46 \%$ \\
\hline Do not know & 43 & 21 & 64 & $12 \%$ \\
\hline Loud snorer (more than talking) & 8 & 6 & 14 & $6.48 \%$ \\
\hline Non -loud snorer (not more than talking) & 121 & 81 & 202 & $93.51 \%$ \\
\hline Snoring frequency (> 1-2 times/wk) & $38(29.45 \%)$ & 47 & 85 & $31.35 \%$ \\
\hline Snoring frequency (more than 3-4 times /wk.) & $91(70.54 \%)$ & 40 & 131 & $60.64 \%$ \\
\hline Bothersome & 17 & 3 & 20 & $9.2 \%$ \\
\hline Non-bothersome & 112 & 84 & 196 & $90.7 \%$ \\
\hline
\end{tabular}

Prevalence of snoring increased with both sexes as age increased. In males, the highest prevalence rate of snoring was obtained in the age group 60-69 years (43.9\%). In this age group 31\% had moderate snoring and $20.6 \%$ habitual snoring. For females, the highest prevalence rate of snoring also occurred at age 60-69years (34.8\%). In the same age group $21.7 \%$ have moderate and $17.3 \%$ habitual snoring. A higher proportion of males had moderate $\&$ habitual snoring from age group of $50-59$ years $\mathrm{p}<0.001$ was significant.

Table II: Age Groups \& Gender Relation.

\begin{tabular}{|c|c|c|c|c|c|c|c|c|c|}
\hline \multirow{2}{*}{$\begin{array}{l}\text { Age } \\
\text { in yr. }\end{array}$} & \multirow{2}{*}{$\begin{array}{c}\text { No, of } \\
\text { participants } \\
\text { in age gr. }\end{array}$} & \multirow{2}{*}{$\begin{array}{r}\text { Total } \\
\text { Snorer }\end{array}$} & \multicolumn{3}{|c|}{ Male Snorer } & \multicolumn{3}{|c|}{ Female Snorer } & \multirow{2}{*}{$\begin{array}{c}\text { \% snorer } \\
\text { in each age } \\
\text { group }\end{array}$} \\
\hline & & & & Moderate & Habitual & & Moderate & Habitual & \\
\hline $20-29$ & 73 & 17 & $9(12.3 \%)$ & 2 & - & $\begin{array}{c}8 \\
(10.9 \%)\end{array}$ & 1 & - & 23.28 \\
\hline $30-39$ & 124 & 20 & $11(8.87 \%)$ & 3 & 1 & $\begin{array}{c}9 \\
(7.2 \%)\end{array}$ & 2 & 1 & 16.1 \\
\hline $40-49$ & 117 & 58 & $39(33.3 \%)$ & $\begin{array}{c}7 \\
17.9 \%\end{array}$ & $\begin{array}{c}6 \\
15.3 \%\end{array}$ & $\begin{array}{c}19 \\
(16.2 \%)\end{array}$ & $\begin{array}{c}3 \\
17.8 \%\end{array}$ & $\begin{array}{c}1 \\
7.1 \%\end{array}$ & 49.57 \\
\hline $50-59$ & 103 & 69 & $41(39.8 \%)$ & $\begin{array}{c}8 \\
19.5 \%\end{array}$ & $\begin{array}{c}7 \\
17.6 \%\end{array}$ & $\begin{array}{c}28 \\
(27.1 \%)\end{array}$ & $\begin{array}{c}6 \\
21.4 \%\end{array}$ & $\begin{array}{c}4 \\
14.2 \%\end{array}$ & 66.99 \\
\hline $60-69$ & 66 & 52 & $29(43.9 \%)$ & $\begin{array}{c}9 \\
31 \%\end{array}$ & $\begin{array}{c}6 \\
20.6 \%\end{array}$ & $\begin{array}{c}23 \\
(34.8 \%)\end{array}$ & $\begin{array}{c}5 \\
21.7 \%\end{array}$ & $\begin{array}{c}4 \\
17.3 \%\end{array}$ & 73.7 \\
\hline
\end{tabular}

$11 \%$ of the males in the age group 40- 69 years had clinically Suspected Obstructive Sleep Apnoea whereas only $8.5 \%$ of females in the same age group 40-69 have clinically Suspected Obstructive Sleep Apnoea. 
Table-III: BMI, CSOSA \& EDS

\begin{tabular}{|c|c|c|c|c|c|c|c|c|}
\hline \multirow[t]{2}{*}{ Age } & \multicolumn{3}{|c|}{ Male Snorer } & \multicolumn{3}{|c|}{ Female Snorer } & \multirow[t]{2}{*}{ BMI $\left(\mathrm{Kg} / \mathrm{m}^{2}\right)$} & \multirow[t]{2}{*}{ EDS } \\
\hline & & & $\mathrm{SA}$ & & & SA & & \\
\hline $20-29$ & 9 & & & 8 & & & $22.5 \pm 3.38$ & 4 \\
\hline $30-39$ & 11 & & & 9 & & & $25.8 \pm 2.78$ & 2 \\
\hline $40-49$ & 39 & 4 & \multirow{3}{*}{$11 \%$} & 19 & 1 & \multirow{3}{*}{$8.5 \%$} & $25.3 \pm 5.43$ & 5 \\
\hline $50-59$ & 41 & 5 & & 28 & 3 & & $30.7 \pm 3.56$ & 7 \\
\hline $60-69$ & 29 & 3 & & 23 & 2 & & $27.6 \pm 4.7$ & 8 \\
\hline
\end{tabular}

CSOSA- Clinically significant obstructive sleep apnoea, EDS -Excessive day time sleeping

\section{Discussion}

The study was done in apparently healthy attendants accompanying patients coming to IMS \& SUM Hospital. Snoring habit confirmed in $40.52 \%$ of participants. $42.7 \%$ of all snorers were males \& $40.2 \%$ of all snorers were females in our result, which was less in comparison to study done by Young et. al [8] In 1993 in his research article on occurrence of sleep disordered breathing among middle-aged adults, he found $81 \%$ women were habitual snorers and $95 \%$ of females were non-habitual snorer \& in males habitual snorers were $66 \%$ and non-habitual snorer were 83\%. Later in 1997 a community study on snoring was done by Olsen et al [9] where 441 subjects were selected within age group of 35-69 years with SRBD (Sleep related breathing disorder) and snoring. The result analysed showed, 56\% men were snorers. Telephonic comparison survey by Ohayon et al ${ }^{[10]}$ found self-reporting snorer in $>65$ years patients than in younger persons. Udwadia et. al[11] observed snoring in $26 \%$ middle aged persons. But, in our study $42.7 \%$ people are snorer which is higher than the study made by Udwadia et.al. However, this difference depends on various factors like awareness among people, smoking \& day time sleepiness and could have influenced the reporting. In our study habitual snoring in both young male and female age group 20-29 years were almost same. As biological development is not complete in adolescent/young adults, there is no significant difference in both gender. However, with progressive age males show significant increase in habitual snoring when compared to females.

In our present study, frequency of snoring increased in both males \& females up to 60-69 years with increasing age. Highest prevalence of snoring for both males \& females was 60-69 year.Clinically suspected obstructive sleep apnoea (CSOSA) was more prevalent in males \& females beyond 40 years. Snoring had a strong relationship with BMI in our study which is also supported by study done by Bloom JW [12]. Cause of
CSOSA during sleep is relaxation of pharyngeal and tongue muscles, blockage of pharyngeal airway by soft tissues or deposition of adipose tissue. Pharyngeal resistance correlates with increasing obesity. Obese adults have a 2-6 fold excess risk of habitual snoring when compared to those with a BMI $<25 \mathrm{~kg} / \mathrm{m}^{2}$. Snoring is also related to increasing day time sleepiness, as measured by ESS. Snoring causes repeated awakening due to hypopnea during night which in turn leads to day time sleepiness. Sleeplessness can be a cause of drowsy driving leading to motor vehicle accidents, CV risks like Hypertension \& Arrhythmias, Type II DM \& decreased efficiency. Paediatric age group with CSOSA usually suffer from concentration deficit. Gold standard for diagnosis of OSA is Polysomnography.

Limitations of our study- More number of cases should be taken $\&$ it should be multi-centric. Additionally, it has been demonstrated that patients are not fully accurate in their assessment of their own problems both in interview and written questionnaires and therefore discrepancies may occur in such method of evaluation.

\section{Conclusion}

Snoring is a common problem in our society which affects day time functioning. The moderate and habitual snorer are of more risk to CVS diseases and metabolic syndrome. Severity of the diseases increases as the age and BMI increases. Considering the large population of our country, the implication of the findings of the current study is substantial and calls for increasing awareness among the health professionals to this neglected but very significant medical health problem which may contribute to the development of serious health problems like systemic hypertension, pulmonary vascular disease, ischemic heart disease, cerebral vascular disease, CCF, arrhythmias and even death. 
Funding: Nil, Conflict of interest: None initiated, Permission from IRB: Yes

\section{References}

1. Richard B. Berry, David P. White, 2John Roper, 1Giora Pillar, 2Robert B. Fogel, 2Michael Stanchina, 2and Atul Malhotra. Awake negative pressure reflex response of the genioglossus in OSA patients and normal subjects. https: // www. researchgate. net/ publication / 10944847_Awake_negative_ pressure_ reflex_response_of_the_genioglossus_in_OSA_patients _and_normal_subjects. J Physiol. 2007 Jun 15; 581 (Pt 3):1193-1205.Published online 2007 Mar 29. doi: 10. 1113/j.physiol.2007.132332.

2. Ng TP, Seow A, Tan WC. Prevalence of snoring and sleep breathing-related disorders in Chinese, Malay and Indian adults in Singapore. Eur Respir J. 1998 Jul; 12(1):198-203.

3. Jones TM, Swift AC. Snoring: recent developments. Hosp Med. 2000 May;61(5):330-5.

4. Rochester, MN, American Sleep Disorders Association, 2001. Obstructive sleep apnea syndrome. In: American Sleep Disorders Association, eds. The International Classification of Sleep Disorders, Revised: Diagnostics and Coding Manual.

5. Gislason T, Aberg H, Taube A. Snoring and systemic hypertension--an epidemiological study. Acta Med Scand. 1987;222(5):415-21.
6. Berlin questionnaire: A Screening tool for OSA.

7. Epworth Sleepiness Scale by Dr Murray Johns.

8. Young T, Palta M, Dempsey J, Skatrud J, Weber S, Badr S. The occurrence of sleep-disordered breathing among middle-aged adults. N Engl J Med. 1993 Apr 29; 328(17):1230-5.

9. Olson LG, King MT, Hensley MJ, et al A community study of snoring and sleep-disordered breathing: prevalence. Am. J. Respir. Crit. Care Med. 1995; 152:711716.

10. Ohayon, MM, Guilleminault, C, Priest, et al, Snoring and breathing pauses during sleep: telephone interview survey of a United Kingdom population sample. BMJ. 1997;314: 860-863.

11. Udwadia ZF, Doshi AV, Lonkar SG, Singh CI. Prevalence of sleep-disordered breathing and sleep apnea in middle-aged urban Indian men. Am J Respir Crit Care Med. 2004 Jan 15;169(2):168-73. Epub 2003 Nov 6.

12. Bloom JW, Kaltenborn WT, Quan SF. Risk factors in a general population for snoring. Importance of cigarette smoking and obesity. Chest. 1988 Apr; 93 (4):678-83.

\section{How to cite this article?}

Devi E, Sahu S, Ray S. Study on snoring habit in healthy population of Eastern Odisha. Int J Med Res Rev 2016;4(9):1571-1575.doi:10.17511/ijmrr.2016.i09.09. 